\title{
THE MEDIATING RELATIONSHIP BETWEEN AUTHENTIC LEADERSHIP, ORGANIZATIONAL JUSTICE \& ENGAGEMENT
}

\author{
Farah Jabbouri \\ Beirut Arab University, Beirut, Lebanon
}

Within today's fast changing and competitive environment, each business aims to be distinguished, more innovative and agile. To do so, all members of an organization need to be engaged, from the janitor all the way to the top. However, encouraging employees to become engaged is never easy. Many scholars thus conclude that organizational fairness is a significant factor in workers' satisfaction. Effective management and leadership styles are often needed to improve employee involvement and company's performance. This research examines the conditions which might lead to better engagement of all employees. In particular, we focus on the two antecedents of engagement: authentic leadership and organizational justice. Two models are thus tested to better understand the mediating relationship between the three variables in question. After an extensive discussion of the obtained statistical results, practical implications of the study along with future recommendations are suggested.

Keywords: authentic leadership; organizational justice; procedural justice; distributive justice; interactional justice; employee engagement

\section{Introduction}

In today's fast-changing and challenging world, every organization seeks to stand out, be more creative, and agile. To do that, everybody within the organization, from a janitor to CEO, must be excited and loyal to their work commitment. To put it another way, every employee must be engaged to the very maximum. This is not a straightforward mission, since it necessitates a great deal of effort. Namely, for this, an organization must have an atmosphere that assumes equal rewards and allows for a transparent dialogue between policy makers and all of their subordinates.

In reality, the collapse of such big and famous businesses as Enron, Arthur Anderson, WorldCom, and Tyco has been taking place due to their leaders' lack of morals in the first

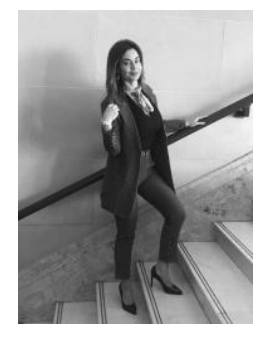

\section{Farah Jabbouri}

Doctor in Business Administration from Beirut Arab University, Lebanon Deputy director of financial affairs and active researcher in Union of Arab Banks.

Research interests : human resources, banking and finance, and management.

Email: jabbourif@gmail.com 
place. As a consequence, the existence of strong leaders who are ethical, brave, optimistic, and dependable is crucial to the progress of any organization. Firms, in particular, need sincere representatives. To be an authentic chief, one must be a legit leader, truthful, and true to oneself. Only truly authentic leaders are really able to encourage confidence among workers. Having a positive and sincere leader is crucial for enhancing employee morale and maintaining company's sustainability (Kim, 2012). In a workplace, such an individual would always have a positive effect on employees' attitudes.

Therefore, the aim of this paper is to explore the mediating impacts of authentic leaders, corporate fairness, and employee involvement.

\section{Problem statement and research purposes}

The paper aims to analyze the link between authentic leadership, corporate justice and employee participation through a review of the related literature as well as an own observatory study. It initially depends on two alternate models: one that provides real leadership as a mediator between various types of organizational justice and commitment, and the other that provides each type of organizational justice for the mediation between genuine leadership and commitment.

The study of two contrasting models thus contributes to the literature on leadership and organizational justice by explicitly questioning their causal relations.

In addition, this study highlights the importance of social fairness and authentic leadership to increase workforce interest in today's workplaces.

This study has been guided by the following research questions:

- RQ1: Are there systemic links between leadership, organizational justice and performance?

- RQ2: Do various forms of organizational justice mediate the relationship between genuine leadership and work commitment?

- RQ3: Can authentic leadership serve as the mediator in the interaction between various kinds of corporate justice and performance?

This paper thus attempts to answer the above questions by collecting and analyzing both qualitative and quantitative data.

\section{Literature Review}

\section{Authentic Leadership and Engagement}

Several researchers have described genuine leadership as an indicator of commitment. For example, (Dirks \& Ferrin, 2002) researched the impact of authentic leadership on involvement in Malaysia using a sample of around 400 workers in their paper "Authentic leadership, confidence, and job engagement".

Authentic leaders instill faith, according to their studies. This is understandable because authentic leaders respect free and direct dialogue, behaving in line with their values, and displaying legal and genuine actions. Employees would value you if you have these values, since anyone will be willing to trust an authentic chief. As a consequence, workers are more involved in work because/when they value their authentic chief (Kim, 2012).

In other terms, employees become more intellectually, physically, and emotionally involved and dedicated to their jobs because/when they have confidence in the authentic 


\section{THE MEDIATING RELATIONSHIP BETWEEN}

chief. Saldana (2013) stated that authentic leadership improves employee participation by growing their interest, motivation, and job satisfaction. To put it another way, authentic leaders' efforts inspire workers to become more motivated and excited towards their jobs. As a consequence, employees are more involved and effective at work.

For corporate success, companies have often put an emphasis on successful human resource management. One of the most important issues for companies is maintaining committed staff and promoting their dedication to the company's ideals (Michael et al, 2011). Job participation has been suggested as a potential response to these challenges, and it has been thoroughly investigated by many scholars.

Engaged workers, according to (Ponnu \& Tennakoon, 2009), are a critical advantage for organizational competitiveness since they allow substantial changes in everyday tasks, thus contributing to organizational efficiency. Ponnu \& Tennakoon (2009) noted that employee job engagement is vital for a company's sustainability, particularly during a downturn, since committed workers work more quickly and efficiently. Leadership becomes a crucial driver in mobilizing an active community inside an organization, while successful leaders may influence workers' job attitudes and behaviors (Qian et al., 2012).

The pervasive ethical breakdowns and lack of confidence between leaders and supporters, on the other hand, has encouraged scholars to seek out new insights on leadership. In this respect, ethical leadership methods have piqued the imagination of scholars who have collected a wide range of data on how to optimize workplace efficiency (Kim, 2012).

Following the optimistic leadership movement, genuine leadership embedded in positivity has been described as an evolving leadership strategy. Authentic leaders, according to many previous studies, are those that make their supporters feel more mentally, emotionally, and cognitively motivated, enabling them to feel more ownership over what they are working for (Kim, 2012). Authentic leaders are often thought to be the key factor in shaping the psychological environment, actions, and success of followers, especially when it comes to job participation (Kim, 2012).

Although many researchers have already looked into the connection between authentic leadership and work engagement (Kim, 2012), it is still rather uncertain how authentic leaders affect followers' work engagement. There is no proof in literature, to the best of our knowledge, that they actually have a direct effect on employee engagement.

According to some studies, genuine leadership has an influence on corporate culture and social identity though (Walumbwa et al, 2010). Simply put, particular behaviors of workers in relation to organizational culture can serve as a connection between authentic leadership and job engagement. Practicing corporate core values may be a particular behavioral element affecting the interaction between genuine leadership and job participation across different organizational culture settings. Since corporate core values not just highlight what is fundamentally relevant for an organization's activities, but also serve as a guidance in executing employees' assignments, the idea of core values has gotten a lot of publicity, from both scholars and practitioners. In this manner, core values allow adherents to accomplish corporate objectives while still finding a greater sense of mission and significance at their work (Walumbwa et al, 2010).

Thus, the first proposed hypothesis can be formulated as follows:

H1: Authentic leadership is positively related to work engagement. 


\section{Authentic Leadership and Organizational Justice}

Connection between leadership and organizational justice is rife with uncertainty. On the one hand, leadership has the ability to bring about corporate fairness. Organizational justice, on the other, can have an effect on the styles of representatives involved. In other words, their influences are very much mutual. Tims et al. (2011) argued that leadership styles may steer employees' focus away from or towards corporate justice. The justice-employee action partnership would be improved by styles that allow workers to concentrate on justice. Models that draw employees' focus away from fairness, on the other side, would have the reverse impact.

For example, transformational leadership places emphasis on justice as transformational leadership requires authentic leadership. As a consequence, authentic leadership can often attract employees' attention to justice. Furthermore, according to the social exchange theory, people's acts are based on others' rewarding responses (Walumbwa et al, 2008). Researchers have been able to describe a number of employee actions in response to their leaders' conduct using the principle of reciprocity, including corporate support, fairness, and encouragement.

Also, authentic leaders are often recognized for their consistent beliefs and openness in their partnerships. Subordinates' impressions of their representatives as trustworthy, open, and equal are influenced by certain characteristics (Creswell, 2009). Employees would view their organization as equal and trustworthy when their chief serves as its logo and spokesman.

As a consequence, authentic leaders have the power to contribute to the development of a trustworthy climate inside an organization. By clearing and fortifying transactional relationships among employees, this confidence helps boost the overall output of a company.

Furthermore, according to the ambiguity management theory, while citizens are unsure, they have a greater response to shifts in justice. This complexity may involve, but is not limited to, a lack of specific and direct knowledge regarding one's business. Authentic leaders, on the other side, are recognized for their consistent principles and partnership honesty, both contributing greatly to confidence.

As a consequence, with authentic management representatives, confusion is always minimized, reducing employee responses to any justice discrepancy. Michael et al. (2011), for example, looked at how six work-life areas influence the relation between genuine leadership and work involvement in their research. Of these six areas, fairness turned out to be the most strongly connected to genuine leadership.

As a consequence, workers who think their representatives are sincere often believe they are also honest. Despite this, they may still feel that their company is unjust. This may happen since the ultimate determination of employee benefits does not entirely depend on the leader/manager, but may also involve owners and/or other top-level executives.

Furthermore, some other managerial practices are also typically determined by company owners and/or top executives (who are not necessarily leaders). As a consequence, although the style of a leader does not have an effect on how workers view fairness, equality in regulation and incentive programs may still contribute to the employee attitudes. In reality, even though organizational results may be unfavorable, workers will be satisfied if they think that the key organizational processes are rational.

As a consequence, procedural fairness has a huge effect on employee support and favorable responses to jobs. In reality, organizational justice can affect the style of a leader 


\section{THE MEDIATING RELATIONSHIP BETWEEN}

who operates a corporation. To offer you an example, procedural justice applies to the protocols of administering the incentives. Reduced prejudice, the usage of correct and appropriate facts in decision-making, and being ethical are also critical facets of procedural justice.

Since these three forms of justice are interconnected, procedural justice has an effect on distributive and interactional justice (Walumbwa et al, 2008). When rules and regulations are transparent and ethical, and judgments are based on relevant and impartial evidence, an organizational climate can foster procedural justice. As a consequence, firm's leadership personalities are developed, and the leader becomes a successful and ethical communicator.

Leadership has been analyzed from a number of viewpoints by now, but ethical issues related to leadership have gained quite narrow coverage. The need to analyze leadership from an ethical viewpoint cannot be overstated, considering the increasing amount of organizational controversies and immoral actions performed by business leaders in different parts of the world. Under the authentic model of leadership, the value of leadership legitimacy is addressed in the first place. Authentic leaders are trustworthy, have a good sense of mission, and are loyal to their core beliefs. As a consequence, they cultivate a more trusting atmosphere within their work environment, thus directly contributing to a variety of beneficial for all results.

The aim of this analysis has been to see how authentic leadership affects subordinates' confidence in their representatives, and how this trust predicts subordinates' job engagement. 395 workers were picked at random from a range of Malaysian banks. ALQ, OTI, and EEQ were among the generic methods used for the analysis here.

In order to assess the factors underlying organizational justice and authentic leadership relational structure the following hypotheses are proposed:

H2: A significant positive correlation takes place between distributive justice and authentic leadership.

H3: A significant positive relationship takes place between procedural justice and authentic leadership.

H4: A significant positive relationship takes place between interactional Justice and authentic leadership.

\section{Organizational Justice and Engagement}

Putting it another way, the more workers feel there is procedural fairness, the more committed they would be. Furthermore, according to a study conducted in an Indian (typically collectivist) society, procedural and interactional justice are positively associated with job participation, with trust mediating this partnership (Wang et al, 2010). That is to add, not just substantive justice, but also interactional justice, have effect on job satisfaction. Furthermore, monetary and non-monetary incentives, as well as distributive justice, promote workplace involvement.

As a consequence, every form of justice actually has some effect on job commitment. In contrast, lack of fairness in the workplace can minimize employees' involvement. When workers think they are not being adequately paid, they get quickly discouraged and bring less effort into their jobs, thus resulting in lower employee participation. Employees tend to regard distributive and procedural fairness as the primary indices of their position in the workplace. Furthermore, employee confusion in this area would have a direct effect on job results, especially when it comes to the interpretation of distributive and procedural justice. 
As a result, the more confused workers feel regarding distributive or procedural fairness, the less committed they would be. Considering all of the above, we can formulate another set of hypotheses as follows:

H5: Work engagement is affected by distributive justice.

H6: Engagement is affected positively by procedural justice.

$\mathrm{H} 7$ : Work engagement is affected positively by interactional justice.

\section{Modeling}

There is a relatively popular opinion that leadership, corporate fairness, and employee participation are incompatible as such. In reality, multiple research on employee attitudes, self-esteem, and community cohesion have found that leadership and fairness have an interactive impact on employee results (Creswell, 2009).

The same author also suggested that transformational leadership tends to moderate the interaction between procedural justice and employee sentiment. Furthermore, according to (Cooper \& Schindler, 2008), transactional leadership moderates the interaction between procedural and distributive justice and job satisfaction. Transformational government, on the other hand, is not a moderator in all the cases of justice-engagement partnership. Nonetheless, according to (Wong et al, 2013), of the six work-life fields, justice is the one most directly connected to authentic leadership. It serves as a connection between genuine leadership and workplace participation. Their studies, though, also indicate that, while workers think their representatives are equal, they may at the same time believe their organization is unfair.

Considering all abovementioned, the aim of our research is to find out why there is such a difference. In order to accomplish the study's aim, two models of mediation for each form of justice are suggested. Organizational justice is represented as mediating the interaction between authentic leadership and job participation in model (a). Model (b), on the other hand, depicts the interaction between corporate justice and job participation as mediated by authentic leadership.

Thus, our final two hypotheses have been formulated as follows:

H8: The relationship between authentic leadership and work engagement is mediated by organizational justice (interactional, distributive and procedural).

H9: Authentic leadership mediates the relationship between organizational justice (interactional, distributive and procedural) and work engagement. 
THE MEDIATING RELATIONSHIP BETWEEN

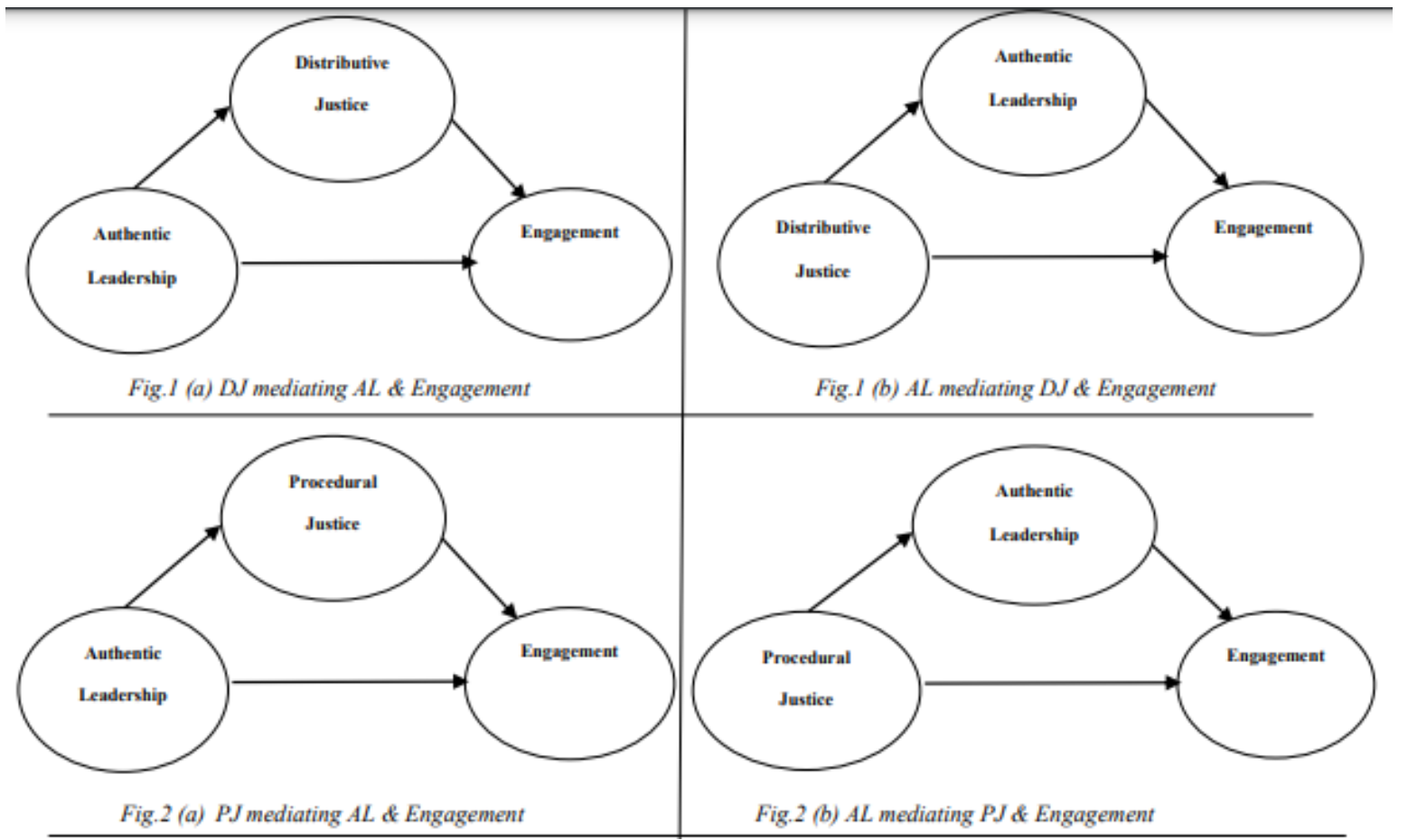



Fig.3 (a) IJ mediating AL \& Engagement

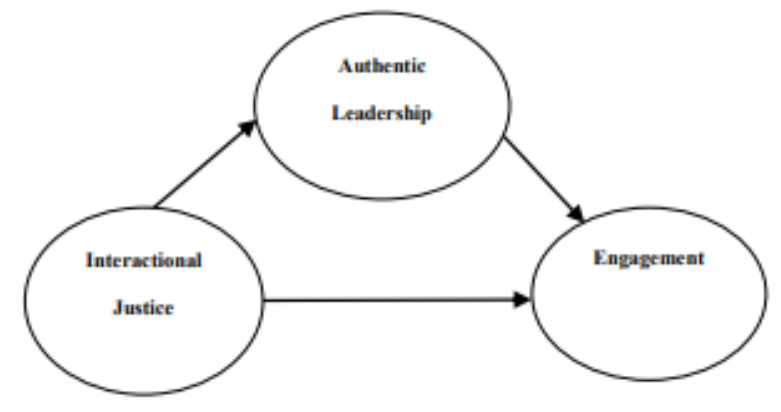

Fig.3 (b) AL mediating $I J \&$ Engagement

Figure 1 - Models of organizational justice

(Source: author's own development and design)

\section{Proposed Method}

\section{Sample}

Between November 2020 and April 2021, the surveys were distributed using Google forms. Employees from a number of privately owned firms were represented in the study's target group. The primary target demographic includes managers, employees, and also MBA/EMBA students.

Furthermore, the survey basically covered any working person who agreed to fill out the questionnaire and could be affiliated within these categories described above. The survey was carried out in English, which is commonly spoken in Lebanon as it is a second or third 
language for quite many people in the country. While 500 people were initially invited for participation, only 302 ended up completing the full survey.

Instruments

The survey starts with a statement describing the study's intent and a promise of the participants' privacy. It has been accepted by the Institutional Review Board (IRB) before distribution.

The survey itself is split into four parts. The first part has seven demographic questions concerning gender, age, education level, industry affiliation, job position and company's size.

The second part of the survey covers 16 questions to determine authentic leadership. On a 5-point Likert scale, the respondents classify their immediate supervisors' degree of honesty, with their answers ranging between 1 ("Not at all") and 5 ("Frequently if not always").

The questions are based on the Authentic Leadership Questionnaire (ALQ, $=0.923$ ) introduced by (Walumbwa et al., 2008). There are four dimensions on that scale: (1) Selfawareness (four items), i.e., knowing how one's behavior effect others; (2) Social Transparency (five items), i.e., revealing the truth; (3) Internalized spiritual perspective/Transparency (four items), i.e., making choices dependent on one's core beliefs; and finally, (4) Balanced processing (three items), i.e., analyzing relevant data before making any judgments.

Further, the third part of the questionnaire deals with career satisfaction. On a 5-point Liker scale ranging from 1 ("Strongly disagree") to 5 ("Strongly agree"), the participants are asked to address 17 questions. Schaufeli et al. developed the Utrecht Work Engagement Scale (UWES) based on Kahn's (1990) concept of engagement, which is used in this analysis $(=0.932)$. The scale assesses three aspects of engagement: (1) vigor (six items), (2) commitment (five items), and (3) absorption (three items).

Niehoff and Moorman's scale also assesses three forms of justice: (1) Distributive Justice (five items), (2) Procedural Justice (six items), and (3) Interactional Justice (three items).

\section{Research Model}

$$
\mathrm{Y}=\mathrm{A}+\mathrm{BX} 1+\mathrm{BX} 2
$$

Employee Engagement = A + B Authentic Leadership + B Organizational Justice,

where:

$$
\begin{aligned}
& \mathrm{Y}=\text { Dependent Variable } \\
& \mathrm{A}=\text { Constant } \\
& \mathrm{B}=\text { Margin Error, } \\
& \mathrm{X}=\text { Independent Variable } / \text { Mediator. }
\end{aligned}
$$

The aim of the mentioned regression is to study the mediating effect of authentic leadership among organizational justice and employee engagement.

The results are tested using regression analysis which is generated after analyzing the data using the SPSS statistical tool. If the margin error shows a level lower than 5\%, this 


\section{THE MEDIATING RELATIONSHIP BETWEEN}

means that there is a direct relationship between authentic leadership, organizational justice and employee engagement, and vice versa.

\section{Regression analysis results}

Several regression analyses can be performed to assess mediation (Baron \& Kenney, 1986). The first regression examined the variables autonomous and contingent. Secondly, the importance of the interaction between the independent variable and the mediator is investigated. The third regression studies the dependent variable with the mediator. The fourth and final regression evaluates the association of the independent variable with the mediator with the dependent variable.

Linear regression predictions are checked with the help of Guass-Markov method. More details on the regressions are given below.

\begin{tabular}{|c|c|c|c|c|c|c|c|}
\hline Dependent & Independent & $\mathbf{N}$ & $B$ & $\mathbf{T}$ & $\mathbf{R}^{2}$ & $\begin{array}{c}\text { Adj. } \\
\mathbf{R}^{2}\end{array}$ & f-sig \\
\hline Engagement & $\begin{array}{c}\text { Distributive } \\
\text { Justice }\end{array}$ & 302 & 0.297 & 6.254 & 0.116 & 0.113 & 0.000 \\
\hline Engagement & $\begin{array}{l}\text { Authentic } \\
\text { Leadership }\end{array}$ & 301 & 0.364 & 8.154 & 0.182 & 0.179 & 0.000 \\
\hline $\begin{array}{c}\text { Distributive } \\
\text { Justice }\end{array}$ & $\begin{array}{c}\text { Authentic } \\
\text { Leadership }\end{array}$ & 302 & 0.292 & 5.432 & 0.090 & 0.087 & 0.000 \\
\hline $\begin{array}{c}\text { Authentic } \\
\text { Leadership }\end{array}$ & $\begin{array}{c}\text { Distributive } \\
\text { Justice }\end{array}$ & 302 & 0.306 & 5.432 & 0.090 & 0.087 & 0.000 \\
\hline \multirow[b]{2}{*}{ Engagement } & $\begin{array}{l}\text { Authentic } \\
\text { Leadership }\end{array}$ & 301 & 0.304 & 6.706 & 0.232 & 0.226 & 0.000 \\
\hline & $\begin{array}{c}\text { Distributive } \\
\text { Justice }\end{array}$ & & 0.204 & 4.391 & & & \\
\hline
\end{tabular}

Figure 2 - Model (1): Distributive Justice, Authentic Leadership and Engagement (author's own development)

The mediatory connection of distributional justice, authentic leadership and commitment is studied in our Model (1). Two forms of interactions between the three variables in question were taken into account. In the first connection, the mediation of distributive justice on authentic leadership and employee commitment is investigated. Conversely, the second one evaluates the mediation of distributive justice and commitment with leadership.

The first regression results are as follows:

$$
\beta=0,297, \mathrm{t}=6,254, \mathrm{f}-\mathrm{sig}=0,00 \text { and } \mathrm{R} 2=0,116 .
$$

Distributive fairness leads to commitment, thus, our hypothesis 2 is confirmed. 
The second regression examines the impact of authentic leadership on commitment and has found that:

$$
\beta=0,364, \mathrm{t}(301)=8,154, \mathrm{R} 2=0,182 \text {. }
$$

This means that authentic leadership reinforces the work commitment to.

The regression of authentic leadership in distributive justice is examined in model 1(a), where distributive justice mediates the connection between authentic leadership and commitment, and the results are as follows:

$$
\beta=0.364, \mathrm{t}=5.431, \mathrm{R} 2=0.090, \mathrm{f}-\mathrm{sig}=0.000 .(302) .
$$

But in the third stage for model 1(b), where the connection between distributive justice and commitment mediates authentic leadership, the reverse is actually observed. In other words:

$$
\beta=0,292, \mathrm{t}(302)=5,432, \mathrm{R} 2=0,0090, \mathrm{f}-\mathrm{sig}=0,000 .
$$

At the fourth and final phase, a multiple regression study has been conducted, which included authentic leadership and distributive justice and commitment as the dependent variable. The Results have been as follows:

$$
\beta=0,304, \mathrm{t}(301)=5,432, \mathrm{R} 2=0,232, \mathrm{f}-\operatorname{sig}=0,000 \text {. }
$$

Authentic leadership results: With respect to distributive justice, $\beta=0.204$, $\mathrm{t}$ (301) $=4.391, \mathrm{R} 2=0.232$, f-sig $=0.000$. This shows that the beta for authentic leadership $(\beta=$ 0,306 ) was less than 0,06 when the regression was applied to all three variables (authentic leadership, distributive justice and commitment), then the beta for authentic leadership ( $\beta=$ $0,364)$. In other terms, the connection between authentic leadership and job commitment is partly mediated by distributive justice.

With distributive justice, the same thing is observed. In regression, the beta for distributive justice ( $\beta=0,204$ ) was less than 0,093 in the regression of distributive justice at Phase $1(\beta=0,297)$, where it is applicable to all the three variables under study (authentic leadership, distributive justice, and engagement).

Authentic leadership mediates in part the interaction between distributive justice and job commitment. Both models are thus statistically accurate. However, the reduction in the path of the coefficient leads us to further insights. As the disparity in distributive justice (0.093) is more than the gap in authentic leadership (0.06), the model 1(b) is seen as better than that for authentic leadership. It represents authentic leadership that mediates the relationship between distributive justice and work commitment. 
THE MEDIATING RELATIONSHIP BETWEEN

\begin{tabular}{cccccccc}
\hline Dependent & Independent & $\mathbf{N}$ & $\boldsymbol{B}$ & $\mathbf{T}$ & $\mathbf{R}^{2}$ & $\begin{array}{c}\text { Adj. } \\
\mathbf{R}^{2}\end{array}$ & f-sig \\
\hline Engagement & $\begin{array}{c}\text { Procedural } \\
\text { Justice }\end{array}$ & 301 & 0.368 & 7.561 & 0.161 & 0.158 & 0.000 \\
\hline Engagement & $\begin{array}{c}\text { Authentic } \\
\text { Leadership }\end{array}$ & 301 & 0.364 & 8.154 & 0.182 & 0.179 & 0.000 \\
\hline $\begin{array}{c}\text { Procedural } \\
\text { Justice }\end{array}$ & $\begin{array}{c}\text { Authentic } \\
\text { Leadership }\end{array}$ & 302 & 0.595 & 14.325 & 0.406 & 0.404 & 0.000 \\
\hline $\begin{array}{c}\text { Authentic } \\
\text { Leadership }\end{array}$ & $\begin{array}{c}\text { Procedural } \\
\text { Justice }\end{array}$ & 302 & 0.683 & 14.325 & 0.406 & 0.404 & 0.000 \\
\hline \multirow{2}{*}{$\begin{array}{c}\text { Authentic } \\
\text { Engagement }\end{array}$} & 301 & 0.246 & 4.326 & 0.210 & 0.205 & 0.000 \\
\cline { 2 - 7 } & $\begin{array}{c}\text { Procedural } \\
\text { Justice }\end{array}$ & & 0.200 & 3.261 & & & \\
\hline
\end{tabular}

Figure 3 - Model (2): Distributive Justice, Authentic Leadership and Engagement (author's own development)

But models have studied the mediatory relationship between procedural justice, authentic leadership and work commitment. The three variables were analyzed in two modes of relation. The first connection assumes a mediation between authentic leadership and participation proceedings. Under the second mode, authentic leadership mediation has been investigated in terms of procedural justice and job commitment. Five regression analyses have been thus performed.

The first regression concerned the process fairness component and participation. The findings were as follows:

$$
\beta=0.368, \mathrm{t}=7.561, \mathrm{R} 2=0.161 \text { and } \mathrm{f}-\mathrm{sig}=.000
$$

Procedural fairness therefore enhances the dedication to work. The next regression, however, has investigated the influence of authentic leadership on loyalty:

$$
\beta=0.364, \mathrm{t}=8.154, \mathrm{R} 2=0.182, \mathrm{f}-\mathrm{sig}=0.000 \text {. }
$$

Thus, authentic leadership inspires employees to become more involved.

The connection between authentic leadership and procedural justice is demonstrated in the model 2(a), with the following:

$$
\beta=0.595, \mathrm{t}=14.325, \mathrm{R} 2=0.406, \mathrm{f}-\mathrm{sig}=0.000 \text {. }
$$

However, in the third step, Model 2(b) showed the contrary:

$$
\beta=0.683, \mathrm{t}=14.325, \mathrm{r} 2=0.406, \mathrm{f}-\mathrm{sig}=0.000
$$

is returned and built for authentic leadership by procedural justice. 
A multiple regression analysis was used in the fourth and last phase, and in it, authentic leadership and procedural justice are included as independent and dependent variables. The findings for authentic leadership reveal that:

$$
\mathrm{t}(301)=3.261, \mathrm{R} 2=0.210, \mathrm{f}-\mathrm{sig}=0.000 \text {. }
$$

With regard to procedural justice $\beta=0.200$ it was found that

$$
\mathrm{t}(301)=3.261, \mathrm{R} 2=.210, \mathrm{f}-\mathrm{sig}=.000 \text {. }
$$

This suggests that when a regression was applied into all three variables (authentic leadership, procedural justice, and engagement), the beta for authentic leadership $(\beta=0,246)$ was less than 0.118 for the beta obtained during step 2 by a regression of authentic leadership $(\beta=0,364)$. In other words, engagement is partially affected by the connection between authentic leadership and commitment.

This supports Hypothesis 8. In the case of the proceedings, the beta process justice was often applied to both of the three factors $(\beta=0.200)$, and was less than the beta resulting from a procedural justice return on stage 1 presence $(\beta=0.368)$ (authentic leadership, proceedings justice and engagement). The relationship between procedural justice and purpose has been partially resolved by authentic leadership.

Therefore, all our models are statistically correct. The decrease in the coefficient is however used to gain additional insights. The best is Model 2(b), except that the difference between betas for procedural justice (0.168) and authentic management is wider (0.118). The relationship between justice and commitment is seen to be impacted by authentic leadership.

\begin{tabular}{cccccccc}
\hline Dependent & Independent & $\mathbf{N}$ & $\boldsymbol{B}$ & $\mathbf{T}$ & $\mathbf{R}^{\mathbf{2}}$ & $\begin{array}{c}\mathbf{A d j} \\
\mathbf{R}^{\mathbf{2}}\end{array}$ & $\mathbf{f - s i g}$ \\
\hline Engagement & $\begin{array}{c}\text { Interactional } \\
\text { Justice }\end{array}$ & 300 & 0.360 & 8.399 & 0.191 & 0.189 & 0.000 \\
\hline Engagement & $\begin{array}{c}\text { Authentic } \\
\text { Leadership }\end{array}$ & 301 & 0.364 & 8.154 & 0.182 & 0.179 & 0.000 \\
\hline $\begin{array}{c}\text { Interactional } \\
\text { Justice }\end{array}$ & $\begin{array}{c}\text { Authentic } \\
\text { Leadership }\end{array}$ & 301 & 0.719 & 16.806 & 0.486 & 0.484 & 0.000 \\
\hline $\begin{array}{c}\text { Authentic } \\
\text { Leadership }\end{array}$ & $\begin{array}{c}\text { Interactional } \\
\text { Justice }\end{array}$ & 301 & 0.675 & 16.806 & 0.486 & 0.484 & 0.000 \\
\hline \multirow{2}{\text{Engagement}}{} & $\begin{array}{c}\text { Authentic } \\
\text { Leadership }\end{array}$ & 300 & 0.197 & 3.260 & 0.219 & 0.214 & 0.000 \\
\cline { 2 - 8 } & $\begin{array}{c}\text { Interactional } \\
\text { Justice }\end{array}$ & 0.227 & 3.866 & & & \\
\hline & & & & & & &
\end{tabular}

Figure 4 - Model (3): Distributive Justice, Authentic Leadership and Engagement (author's own development) 


\section{THE MEDIATING RELATIONSHIP BETWEEN}

Model (3) analyses interactional justice, authentic leadership with engagement as mediation. The three variables in question have two modes of their relationship. The first one addresses the mediation of interactional justice in authentic leadership and engagement. The second relationship explores the mediation between interactional justice and leadership in engagement.

The first regression uses interactional justice as the independent variable. The values obtained are as follows:

$$
\beta=0.360, \mathrm{t}=8.399, \mathrm{R} 2=.129, \mathrm{~F}-\mathrm{Sig}=.000 .
$$

These results suggest that interactional justice leads to increased functional engagement.

The second regression examines the effect of authentic leadership on commitment and engagement. It also reinforces authentic leadership influences the participation at work. In our Model 3(a), authentic leadership in interactional justice has been regressed with the following results:

$$
\beta=0.719, \mathrm{t}=16.806, \mathrm{R} 2=0.486, \mathrm{f}-\mathrm{sig}=0.000 \text {. }
$$

However, in Model 3(b), the third step reveals the following:

$$
\beta=0.675, \mathrm{t}=16.806, \mathrm{R} 2=0.486 \text {, and } \mathrm{f}-\mathrm{sig}=0.000 \text {. }
$$

A multiple regression analysis, with authentic leadership, interactional justice and engagement as dependent variables, took place in the fourth and last phase. The results indicate that:

$$
\beta=0,197, \mathrm{t}=3.26 \text {, and } \mathrm{R} 2=0,219 . \mathrm{f}-\mathrm{sig}=0,00 .
$$

The findings for interactional justice were as follows:

$$
\beta=0.227, \mathrm{t}=, \mathrm{R} 2=0.219 \text { and } \mathrm{f}-\mathrm{sig}=0.000 \text {. }
$$

This shows that for all three parameters under study here (authentic leadership, interaction fairness and commitment) the Beta for authentic leadership $(\beta=0.197)$ was less than 0.167 while for commitment it was $(\beta=0.364)$.

In its turn, interactional justice was part of the connection between authentic leadership and commitment. The same has been also proved for interactional justice. When all three factors (authentic leadership, relationship justice and commitment) were regressed, the Beta for interactional justice was not as strong as $0.133(\beta=0.227)$, as the Beta was obtained from a step 1 reversal of interactional justice $(\beta=0.36)$.

The relation between interactional justice and work commitment was thus partly mediated by authentic leadership. Therefore, all our models are statistically correct. The best model is Model 3a, as its beta for authentic leadership is more clearly defined (0.167). It demonstrates the link between authentic leadership and commitment at work. 


\section{Discussion}

Many researchers were trying to get a better understanding of the effects of organizational justice on the attitudes among staff members. Dealing with the problem of authentic leadership as well as job commitment among professionals, Wong et al. (2013) examined the mediation in six work-related areas - workload, supervision, compensation, culture, justice and values. Their study proved that there is an important correlation between justice at work and authentic leadership. Employees often think their organization is unfair, considering a close association between honesty and equity. Such mixed results can be attributed to "larger, unequal business choices" as formulated by Wong et al. (2013).

This research explores the mediating connection between authentic leadership and organizational justice in working interaction, and partly it explains the previous contradictory findings. Our findings also suggest that authentic leadership mediates in part the connection between distributive and procedural justice within the work environment.

Our 1(b) and 2(b) models are proved to be appropriate. When interactional justice is checked, this relationship is inverted. In other words, the connection between authentic leadership and work commitment partly mediates interactional justice, as demonstrated in our Model 3 (a).

However, some theorists have also considered the expansion of procedural justice to become interactional. This can be the case when procedural justice is temporarily excluded from the equation, since its scale is the weakest. Thus, the findings have been reversed since procedural justice has been seen to be mediating authentic leadership and commitment to work.

In practice, the same can be done with interactional justice. This finding may take place in real life in cases when inside an organization there is an atmosphere in which employees are not satisfied and are accusing their manager(s) of prejudice.

However, in our specific case, this factor had the lowest connection to the scale, primarily due to the optimistic atmosphere detected; thus, justice has been mainly seen as one variable. This is why in our calculations; the mean of procedural justice was reported that way. In addition, if all three forms of justice are merged into one latent variable (organizational justice), the connection between authentic leadership and commitment is surely mediated by it.

In other terms, workers who feel they are being handled equally regard themselves within the company as important, necessary and valued persons. In addition, employees expect high-level bosses to have the ultimate say in their paychecks and promotions rather than their immediate management.

This shows that processes and cash incentives motivate work rather than the actual leadership. In addition, the study indicates that the role of authentic leadership explains part of the connection between these two forms of participation in justice processes, distribution and function. In general, leaders are the organization's delegates and those who enforce laws. The fact that authentic leaders are sincere, confident and are able to bring their views into the enterprise is equally significant. 


\section{THE MEDIATING RELATIONSHIP BETWEEN}

\section{Practical Implications}

This research explores something many researchers have been trying to understand for a while to date: how fairness might influence the behavior of staff. And also, how it contributes to organizational justice, empowerment and employee engagement. In this regard, our results pave the way to a deeper analysis of justice in leadership. In this context, authentic leadership is worth identifying as a mediator of two forms of organizational justice and commitment.

On their side, organisations are doing their best to grow and enhance/improve their workers' degree of participation in the internal processes and activities. To do this, it is necessary to establish, inter alia, equal procedures. Therefore, companies must clarify explicitly their procedures, rules and regulations, and first and foremost - the offered incentives. This is one of those tasks that belong to authentic leadership. Organizations need to learn honesty and leadership abilities, both of them must be explicitly manifested by their managers/leaders.

\section{Limitations}

Our data was gathered from a survey, thus, all the knowledge was very much opinionbased. By now, it has been already well established that it is somewhat difficult for many workers to tell the actual facts when it comes to their employers and their organisations. In everyday life, many employees have troubles singling out facts from their own emotions. The duration of the questionnaire was another weakness. Furthermore, most of the people surveyed were aged between 18 and 34, older generations happened to be somewhat underrepresented. This can be partially explained by the context in which our analysis has been carried out. Older participants were very much dubious about the study's confidentiality, despite all the explanations provided from the very beginning. Online respondents may have been more comfortable, since online surveys usually look more confidential as such.

\section{Future Research Recommendations}

Obviously, more studies are needed in the fields of authentic leadership, organizational justice and working commitment since links between these three still need to be properly understood. The effects of transformational leadership on the correlation between organizational justice and work commitment can be analyzed by scholars in the future. At this, authentic leadership should probably be perceived as part of transformational leadership.

The analysis of all leadership styles in terms of moderation and not as mediation is another suggestion for future research. Moderation may have different effects and enable the dynamics between all three variables in question to be seen in more detail.

Moreover, each model may be also studied taking gender differences into account. This

may provide a clearer view on the gender impacts of such influences. Other demographic factors can be considered, such as employment status and years of expertise in the field.

Finally, similar future studies can and should be carried out in various other sectors as well since each sector has its own qualifications, tasks and requirements. Similar modelling but another sector would certainly reveal a very different nature of the relationship between 
the three variables in question. Also, since this research has been cross-sectional, it is worth considering a longitudinal study since any sort of relationships within a working environment tend to seriously change over time.

\section{References:}

Cooper, D.R., \& Schindler, P.S. (2008). Business Research Methods, McGraw-Hill/Irwin.

Creswell, J. (2009). Research Design. Qualitative, Quantitative, and Mixed Methods Approaches. California: SAGE Publications, Inc.

Dirks, K.T., \& Ferrin, D.L. (2002). Trust in leadership: Meta-analytic findings and implications for research and practice. Journal of Applied Psychology, 87(4), 611-628.

Kim, B.R. (2012). The relationship between a team leader's behaviors aligned with organizational core values and follower's organizational commitment: based on mediating effect of trust in the team leader. Master Thesis, Korea University, Seoul.

Saldana, J. (2013). The Coding Manual for Qualitative Researchers. California: SAGE Publications, Inc.

Michael, S.W., Adela, C.S., \& Jerel, E.S. (2011). Work engagement: a quantitative review and test of its relations with task and contextual performance. Personnel Psychology, 6 (1), 89-136.

Ponnu, C.H., \& Tennakoon, G. (2009). The Association between Ethical Leadership and Employee Outcomes - the Malaysian Case. Electronic Journal of Business Ethics and Organization Studies, 14 (1), 21-32.

Qian, J., Lin, X., \& Chen, G.Z. (2012). Authentic leadership and feedback-seeking behavior: an examination of the cultural context of mediating processes in China. Journal of Management and Organization, 18 (3), 286-299.

Tims, M., Bakker, A.B., \& Xanthopoulou, D. (2011). Do transformational leaders enhance their followers' daily work engagement? The Leadership Quarterly, 22 (1), 121-131.

Walumbwa, F., Avolio, B., Gardner, W., Wernsing, T., \& Peterson, S. (2008). Authentic leadership: development and validation of a theory based measure. Journal of Management, 34(1), 89-126.

Walumbwa, F.O., Wang, P., Wang, H., Schaubroeck, J., \& Avolio, B.J. (2010). Psychological processes linking authentic leadership to follower behaviors. The Leadership Quarterly, 21 (5), 901-914.

Wong, C., Laschinger, H., \& Cummings, G. (2010). Authentic leadership and nurses voice behavior and perceptions of care quality. Journal of Nursing Management, 18 (8), 889-900.

Paper submitted

Paper accepted for publishing

Paper published online
01 March 2021

18 April 2021

31 May 2021 